ninhydrin-reacting substances present in a normal plasma and in normal spinal fluid, prepared as described above.

\section{DISCUSSION}

The combined ionophoretic-chromatographic technique has certain advantages over conventional two-way chromatography. This method is rapid. Time is saved by: (a) replacing the $24 \mathrm{hr}$. first run in phenol with high-voltage electrophoresis taking $1 \frac{1}{2} \mathrm{hr}$.; (b) eliminating the need for desalting; (c) for protein-containing fluids (plasma etc.), avoiding the tedious process of ultrafiltration, which is replaced by a simple deproteinization with picric acid followed by centrifuging. The entire operation can be completed in 9-10 hr. instead of the $48 \mathrm{hr}$. required by two-way chromatography.

There is better separation of certain amino acids. For example, methionine separates from leucine, whereas in the phenol-lutidine chromatogram these spots overlap, and oxidation is necessary to detect the presence of methionine (Dent, 1947). Asparagine produces a distinct spot and does not overlap glycine. Cystathionine, argininosuccinic acid and phosphoethanolamine are more distinctly separated from each other. $\beta$-Aminoisobutyric acid separates well from histidine. On the other hand, glutamine and glutamic acid are not so well separated as they are by two-way chromatography, and the 1- and 3-methylhistidines overlap histidine.

The spots are rounder and more compact than with two-way chromatographic techniques. The electrophoretic separation allows very little diffusion of the spots, because of the short time required to traverse a given distance. As a result of the automatic desalting during electrophoresis, the final chromatogram shows little distortion of the spots. Another advantage is that volatile substances such as ethanolamine are often found in pathological urines when not detected in the same specingen by routine chromatography.

\section{SUMMARY}

1. A technique for two-way separation of amino acids and other ninhydrin-reacting substances by high-voltage paper electrophoresis followed by paper chromatography is described, which gives more rapid separation than two-way paperchromatographic methods.

2. The method is particularly useful for the study of plasma and spinal fluid, because these fluids can be deproteinized in a few minutes with picric acid, thus eliminating the tedious process of ultrafiltration. Moreover, desalting is not necessary, as it is automatically accomplished during the electrophoresis run.

3. A map is presented showing the positions taken by 43 ninhydrin-reacting substances when separated by this method.

The author is indebted to Professor C. E. Dent and to Mr R. G. Westall for constant advice and encouragement, to Dr D. C. Cusworth for help with amino acid chromatography, and to Mr C. E. Glover and Mr G. Marshall for construction and maintenance of apparatus.

\section{REFERENCES}

Consden, R. \& Glynn, L. E. (1955). Lancet, 1, 943.

Dent, C. E. (1947). Biochem. J. 41, 240.

Dixon, G. H., Kauffman, D. L. \& Neurath, H. (1958). J. biol. Chem. 233, 1373.

Durrum, E. L. (1950). J. Amer. chem. Soc. 72, 2943.

Durrum, E. L. (1951). J. Colloid Sci. 6, 274.

Gross, D. (1955). Nature, Lond., 176, 72.

Gross, D. (1956). Nature, Lond., 178, 29.

Honegger, C. G. (1956). Helv. chimica acta, 39, 1671.

\title{
The Isolation and Characterization of Acetylcholine- Containing Particles from Brain
}

\author{
By V. P. WHITTAKER \\ Agricultural Research Council Institute of Animal Physiology, Babraham, Cambridge
}

(Received 28 January 1959)

Chemical transmission at nerve endings is now being increasingly discussed in terms of the 'synaptic vesicle' theory (del Castillo \& Katz, 1956; Eccles, 1957; Hebb, 1957). Synaptic vesicles are small bodies about $0.05 \mu$ in diameter observable in electron micrographs of thin sections of nervous tissue and concentrated in large numbers at many different kinds of nerve endings (de Robertis \& Bennett, 1955; de Robertis \& Franchi, 1956; Robertson, 1956; Palay, 1956; Luft, 1956); they are assumed to contain chemical-transmitter substances (e.g. acetylcholine in cholinergic neurones) which are released in response to the arrival of a nerve impulse. 
This theory provides a reasonable explanation of a number of facts about chemical-transmitter substances. The 'quantized' release of acetylcholine at neuromuscular junctions detected electrophysiologically by del Castillo \& Katz (1956) might be brought about by the spontaneous or synchronized bursting of such vesicles. The coexistence in the same tissue of transmitter substances and enzymes which rapidly destroy them in vitro, also of receptor sites, implies the existence of permeability barriers which might be provided by the walls of the vesicles. Acetylcholine and other putative transmitter substances are known to exist in nervous tissue partly in a 'bound' form. The properties of 'bound' acetylcholine suggest that it is acetylcholine held in some kind of subcellular structure analogous to or perhaps identical with mitochondria (Bodian, 1942; Feldberg, 1945; Braganca \& Quastel, 1952 ; Brodkin \& Elliott, 1953; Stone, 1955).

Hebb \& Whittaker (1958) have recently described the isolation of a subcellular fraction of brain tissue distinct from mitochondria, nuclei and microsomes, which contains the bound acetylcholine and choline acetylase. It seemed possible that this fraction might represent a preparation of synaptic vesicles. Accordingly, the fraction has been further studied biochemically and morphologically from this point of view. It has been found to consist largely of particles having the same size range as that re. ported for synaptic vesicles and distinct in size, structure and enzyme content from mitochondria. The distributions of 5-hydroxytryptamine, another compound for which a transmitter action in the central nervous system has been proposed, and of two lysosome enzymes, acid phosphatase and $\beta$ glucuronidase, were compared with that of acetylcholine in order to throw light on the degree of homogeneity of the acetylcholine-containing fraction. The distribution of 5-hydroxytryptamine resembled that of acetylcholine. The two lysosome enzymes gave conflicting results and suggested that the lysosome hypothesis cannot be applied to brain without modification. Finally, the conditions influencing the release of acetylcholine from the particles have been studied in an attempt to find out how far their properties can account for the phenomenon of bound acetylcholine and to elucidate the mechanism of acetylcholine release in vivo.

Preliminary accounts of part of this work have already been given (Whittaker, 1958 $a, b, 1959$ ).

\section{METHODS}

\section{Estimation of pharmacologically active substances and enzymes}

Free and bound acetylcholine. Assays of acetylcholine were carried out on the rectus abdominis muscle of the frog
(Chang \& Gaddum, 1933). To determine total acetylcholine, the bound ester was first released by treating the sample at pH 4 and $100^{\circ}$ for $10 \mathrm{~min}$. Since shaking with ether also releases all the bound acetylcholine, this method was also used in some experiments. Free acetylcholine was determined by assaying samples directly without prior treatment. The difference between the total and free acetylcholine content of a sample was taken to represent the bound acetylcholine therein.

The presence of sucrose in the organ bath was found to modify the response of the muscle to acetylcholine; this was allowed for by the addition of sucrose to the standards. High concentrations of sucrose caused a contraction in the absence of acetylcholine; this made the assay of low concentrations of acetylcholine in such solutions difficult, but the difficulty could be avoided when the acetylcholine content of particles was being assayed by resuspending the particles in $0.32 \mathrm{~m}$-sucrose before releasing acetylcholine by acid treatment.

Assay of 5-hydroxytryptamine. This was carried out by the rat-fundus method of Vane (1957), atropine $(0 \cdot 2 \mathrm{mg} . / \mathrm{ml}$.) being added to the medium to block acetylcholine.

Succinic dehydrogenase. This was estimated manometrically at $37^{\circ}$ according to Hogeboom, Claude \& Hotchkiss (1946), as modified by W. N. Aldridge \& M. K. Johnson (personal communication). The hydrogen acceptor was $0.2 \mathrm{ml}$. of $0.25 \mathrm{M}-\mathrm{K}_{3} \mathrm{Fe}(\mathrm{CN})_{6}$ in $0.023 \mathrm{M}-\mathrm{NaHCO}_{3}$, placed in the side bulbs of Warburg flasks. The main compartment contained enzyme in $1.0 \mathrm{ml}$. of $0.32 \mathrm{M}$-sucrose and $1.8 \mathrm{ml}$. of a medium consisting of $0.14 \mathrm{ml}$. of $2 \mathrm{M}-\mathrm{MgCl}_{2}, 0.5 \mathrm{ml}$. of $0.1 \mathrm{M}$-ethylenediaminetetra-acetic acid, $1.0 \mathrm{ml}$. of $\mathrm{M}$ phosphoric acid, $6.0 \mathrm{ml}$. of $0.3 \mathrm{M}$-succinic acid and $4.0 \mathrm{ml}$. of $0.27 \mathrm{M}-\mathrm{NaHCO}_{3}$ in a final volume of $30 \mathrm{ml}$. The other ingredients of the medium were adjusted to $\mathrm{pH} 7 \cdot 4$ before the $\mathrm{NaHCO}_{3}$ solution was added. The flasks were gassed with $\mathrm{CO}_{2}+\mathrm{N}_{2}(5: 95, \mathrm{v} / \mathrm{v})$, and after temperature equilibration the reaction was started by tipping in the side-bulb contents. The rate of displacement of $\mathrm{CO}_{2}$ from the bicarbonate buffer by the $\mathrm{H}^{+}$ions formed during the reduction was taken as a measure of the enzyme activity, 1 unit (u.) of which $=1 \mu \mathrm{l}$. of $\mathrm{CO}_{2} / \mathrm{hr}$. Measurements were average of duplicate determinations made during the first 6 min. of the reaction. Flasks with no enzyme were included as controls, but the correction for non-enzymic $\mathrm{CO}_{2}$ evolution was usually negligible.

Acid phosphatase. This was estimated in $0 \cdot 1 \mathrm{~m}$-citrate buffer, pH 4.9, using 0.05 M-phenylphosphate as substrate as described by Cohn \& Richter (1956), or in a few experiments by the method of Berthet \& de Duve (1951), with sodium $\beta$-glycerophosphate as substrate after activating the enzyme by mechanical disruption of the particles in a Mickle shaker. The use of the first method was considered to be legitimate owing to the absence of glucose 6-phosphatase from brain and was preferred to the other as more sensitive, enabling fractions to be fully activated by dilution. The two methods gave similar results. Activities are expressed as $\mu \mathrm{g}$. of $\mathrm{P}$ liberated $/ \mathrm{hr}$.

$\beta$-Glucuronidase. This was estimated by the method of Kerr \& Levvy (1951). Activity is expressed in glucuronide units (G.U.) as defined by these authors.

Cholinesterase. 1 unit (u.) is that amount of enzyme which releases $1 \mu \mathrm{l}$. of $\mathrm{CO}_{2} / \mathrm{min}$. from $10 \mathrm{~mm}$-acetylcholine in $\mathrm{CO}_{2}-\mathrm{NaHCO}_{3}$ buffer, $\mathrm{pH} 7 \cdot 4$ at $37^{\circ}$. 
Expression of activities. Activities of fractions are expressed $/ \mathrm{ml}$. fraction or/volume of fraction equivalent to $1 \mathrm{~g}$. of fresh brain tissue, as percentages of the total recovered activity, or as relative specific activities. This last quantity is defined as the activity of the fraction expressed as a percentage of the total recovered activity divided by the nitrogen content of the fraction as a percentage of the total recovered nitrogen.

Nitrogen estimations. These were carried out by the microKjeldahl method.

Electron microscopy. This was carried out on sections (approximately $200 \AA$ thick) of fractions fixed and stained in $\mathrm{OsO}_{4}$ and embedded in methyl methacrylate resin. The sections were cut by $\mathrm{Dr}$ K. M. Smith and the electron micrographs were taken by $\mathbf{M r}$ G. J. Hills. Fractions were diluted with an equal volume of $2 \%(w / v) \mathrm{OsO}_{4}$ in $0.32 \mathrm{M}$ sucrose, adjusted to pH 7.4 with $\mathrm{NaOH}$ and centrifuged at $8 \times 10^{5} \mathrm{~g}$-min., and the pellet was embedded after storage overnight at $0-2^{\circ}$.

\section{Fractionation of brain tissue}

Preparation of primary fractions. The preparation and fractionation of homogenates of rabbit and guinea-pig brain in $0.32 \mathrm{M}$-sucrose containing $50 \mu \mathrm{M}$-eserine into 'nuclear' $\left(P_{1}\right)$, 'crude mitochondrial' $\left(P_{2}\right)$, 'microsomal' $\left(P_{3}\right)$ and 'cytoplasmic' $(S)$ fractions were carried out as described by Hebb \& Whittaker (1958), with some modifica-
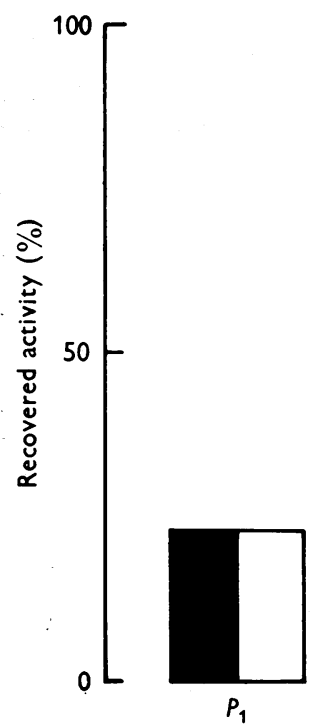
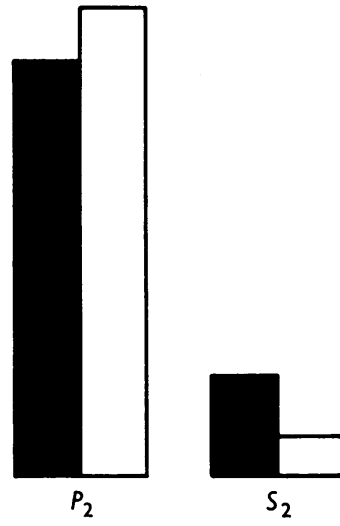

tions. Thus the microsomal and cytoplasmic fractions were often not separated but studied as a combined fraction $\left(S_{2}\right)$. In most experiments, a glass and Perspex homogenizer (rotating at $840 \mathrm{rev} . / \mathrm{min}$.) with a difference in diameter of $0.025 \mathrm{~mm}$. between pestle and mortar (W. N. Aldridge, personal communication) was used instead of the all-glass homogenizer, with a somewhat greater and variable clearance, previously used. Sometimes eserine was omitted from the sucrose; under these circumstances the free acetylcholine of the supernatant fraction was destroyed and the total acetylcholine content of the homogenate was lower by a like amount. In some experiments, the yield of acetylcholine particles in the $P_{2}$ fraction was improved by washing the $P_{1}$ fraction twice with sucrose and by sedimenting the $P_{2}$ fraction in an integrated field of 8 instead of $4.5 \times 10^{5} \mathrm{~g}$-min. (The gravitational effect of centrifuging is expressed in $g$-min., i.e. the product of the force and the time, in minutes, of spinning.) Variations in the fractionation procedure were controlled by phase-contrast microscopy and by determinations of bound acetylcholine and succinic dehydrogenase (SDH). A typical result is given in Fig. 1, from which it will be seen that the two activities parallel each other closely in their distribution in the

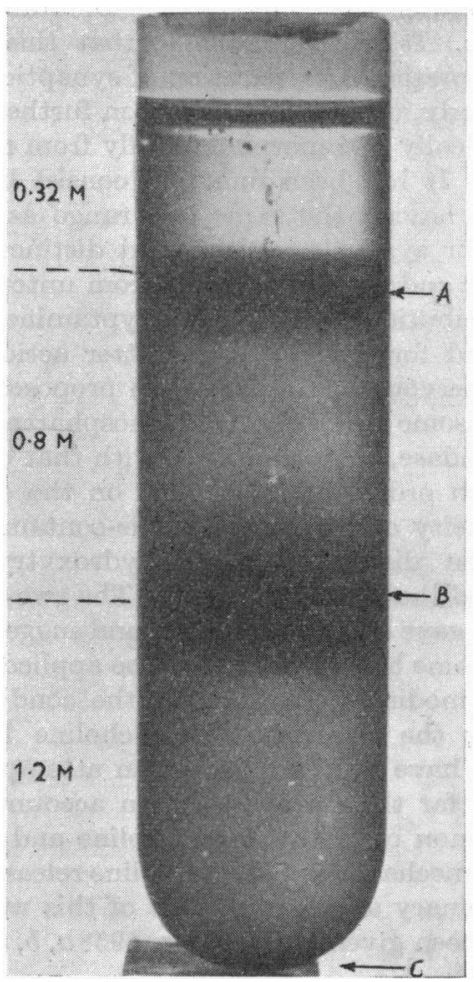

Fig. 1. Distribution of bound acetylcholine (D) and succinic dehydrogenase (SDH) ( $\square$ ), expressed as a percentage of the total recovered activity between the twice-washed nuclear fraction $\left(P_{1}\right)$, crude mitochondrial fraction $\left(P_{2}\right)$, and microsomal plus cytoplasmic fraction $\left(S_{2}\right)$, from guinea-pig brain. The $P_{2}$ fraction was separated at $8 \times 10^{5} \mathrm{~g}$-min. Activity of original homogenate: acetylcholine, $11.7 \mu \mathrm{m} \cdot \mathrm{moles} / \mathrm{g}$. of fresh tissue; SDH, $9900 \mathrm{u} . / \mathrm{g}$. of fresh tissue. Recovery of activity in fractions: acetylcholine, $91 \%$; SDH, $80 \%$. The results are the average of four experiments.

\begin{abstract}
primary fractions. Since SDH is generally considered to
\end{abstract}


be exclusively located in mitochondria, it is clear in confirmation of previous findings that the bound acetylcholine is located in particles which have sedimentation properties broadly similar to these of mitochondria and that the activities of $P_{1}$ and $S_{2}$ are due to contamination of these fractions by $P_{\mathbf{2}}$.

Subfractionation of the $P_{2}$ fraction. Subfractionation of $P_{2}$ by equilibrium centrifuging in density gradients was carried out as described by Hebb \& Whittaker (1958), the SW 39 head of the Spinco Model L preparative ultracentrifuge being used. In the simplified procedure used, the $P_{2}$ fraction was resolved into three main subfractions, $A, B$ and $C$, by centrifuging $1 \mathrm{ml}$. quantities into a density gradient consisting of $2 \mathrm{ml}$. of $1.2 \mathrm{M}$ - and $2 \mathrm{ml}$. of $0.8 \mathrm{M}$ sucrose in an integrated field of about $7.5 \times 10^{6} \mathrm{~g}$-min. (Fig. 2). $A$ was white material of density intermediate between that of $0.32 \mathrm{M}$ - and $0.8 \mathrm{M}$-sucrose, largely inactive and consisting mainly of the largest $(2-5 \mu)$ particles in $P_{2}$; $B$ was greyish white material of density intermediate between that of $0.8 \mathrm{M}$ - and $1.2 \mathrm{M}$-sucrose, containing most of the acetylcholine and consisting of the smallest particles in $P_{2}$; while $C$ was a tan-coloured precipitate of material more dense than 1.2 M-sucrose, containing most of the SDH, little acetylcholine and large numbers of typical rod-shaped mitochondria. The sub-fractions were separated in the cutter by sections through the relatively clear zones of sucrose between them. The particles contained in them were returned to $0.32 \mathrm{~m}$-sucrose for assay and storage by diluting with water to bring the sucrose concentration to $0.32 \mathrm{M}$, centrifuging in an integrated field of $8 \times 10^{5} \mathrm{~g}$-min. or more and resuspending the precipitate in $0.32 \mathrm{M}$-sucrose. A sample of the parent fraction, made $M$ with solid sucrose, was similarly diluted, centrifuged and resuspended as a control. In contrast with some earlier results, this process of dilution and resuspension could be achieved with little or no loss of bound acetylcholine, provided that the particles were not exposed to hyperosmotic conditions for too long.

The use of the SW 39 head suffered from the disadvantage of providing only very small quantities of material in each run. Accordingly in some experiments the differences in density were utilized for larger-scale separations in the Spinco no. 40 head. Centrifuging in a density gradient is not conveniently carried out in this head as, owing to the fixed inclination of the tubes, boundaries change position and layers overlap during runs. However, it was possible to effect separations by first centrifuging samples of $P_{2}$ into a fairly large volume of $0.8 \mathrm{M}$-sucrose, leaving the relatively large light particles corresponding to subfraction $A$ at the top of the tube, and then separating the mixture of denser particles corresponding to subfractions $B$ and $C$ in a second run with $1.2 \mathrm{M}$-sucrose. The procedure is illustrated diagrammatically in Fig. 3 and analyses of the fractions from one of these experiments are presented in Table 1 . It will be seen that although fraction $A$ retained appreciable amounts of acetylcholine and SDH, most of the recovered acetylcholine was present in fraction $B$ and most of the recovered SDH was present in fraction $C$. The relative

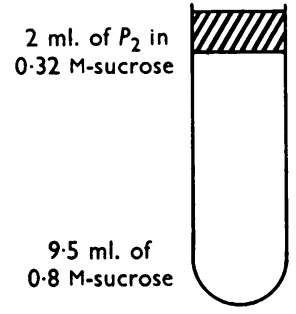

(a)

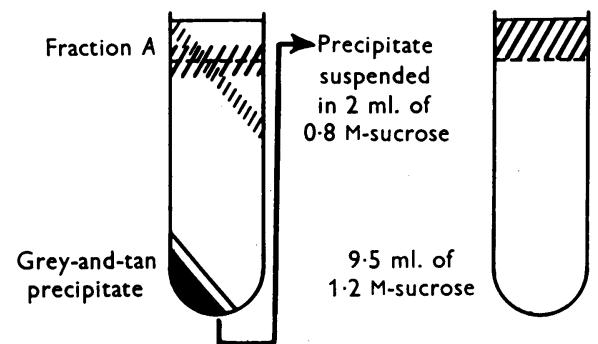

(b)

(c)

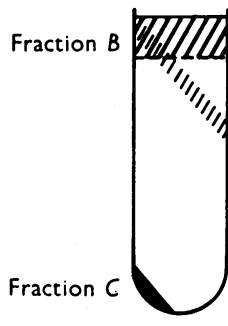

(d)

Fig. 3. Appearance of centrifuge tube $(a)$ before, $(b)$ after centrifuging $2 \mathrm{ml}$. of $P_{2}$ from rabbit brain into $9 \cdot 5 \mathrm{ml}$. of $0.8 \mathrm{M}$-sucrose in the no. 40 head of the Spinco Model L preparative ultracentrifuge. Fraction $A$ was collected, the intermediate clear zone discarded and the precipitate resuspended in $2 \mathrm{ml}$. of its supernatant, transferred to a second tube containing $9.5 \mathrm{ml}$. of $\mathbf{1} \cdot 2 \mathrm{M}$-sucrose shown $(c)$ before and $(d)$ after centrifuging similarly. Corresponding fractions from two tubes were pooled for analysis (Table 1).

Table 1. Acetylcholine, succinic dehydrogenase and nitrogen content of subfractions of $P_{2}$

For details and for definition of relative specific activity (RSA) see Methods.

$\begin{array}{lccccc}\text { Fraction } & \overbrace{\begin{array}{c}\text { Recovered } \\ \text { activity } \\ \text { recovered }\end{array}}^{\text {Acetylcholine }} & \text { RSA } & \overbrace{\begin{array}{c}\text { Recovered } \\ \text { activity } \\ (\%)\end{array}}^{\text {SDH }} & \text { RSA } \\ A & 53 & 33 & 0 \cdot 62 & 13 & 0 \cdot 25 \\ B & 30 & 67 & 2 \cdot 1 & 16 & 0 \cdot 53 \\ C & 17 & 0 & 0 & 71 & 4 \cdot 2 \\ \text { Recovery* } & 76 & 96 & - & 58 & -\end{array}$

* As percentage of $P_{2}$ (from rabbit brain). Composition: N, 3.78 mg./ml.; acetylcholine, $2.9 \mu \mathrm{m}-\mathrm{moles} / \mathrm{ml}$.; SDH, 5560 u./ml. 
specific activities (cols. 4 and 6) also emphasize the different distribution of the two activities in the fractions.

When fraction $B$, thus prepared, was refractionated in a density gradient consisting of layers of $1.2 \mathrm{M}$-, $\mathrm{M}$ - and $0.8 \mathrm{M}$ sucrose, with the SW 39 head, most of the particles migrated as a single dense white band to a position just above the $1.2 \mathrm{~m}$ layer, indicating a density equivalent to that of M-sucrose, i.e. of about $1.15 \mathrm{~g} . / \mathrm{ml}$. at $20^{\circ}$. Most of the acetylcholine remained in association with this band. A small proportion of the particles and of the acetylcholine was recovered in two other faint zones in adjacent layers, indicating that the particles vary no more in density than by about $\pm 3 \%$ of the mean.

\section{RESULTS}

\section{Electron microscopy of subfractions}

Electron micrographs of fractions $B$ and $C$ (from guinea-pig brain) are shown in Plate $4(2,3)$. Most of the particles in fraction $C$ [Plate 4 (3)] having the high SDH content are typical mitochondria show. ing the characteristic structure of limiting membrane and internal cristae mitochondriales. Their appearance closely resembles that of rat-liver mitochondria isolated from sucrose homogenates (Novikoff, 1957); there is internal vesication; some mitochondria are swollen and have lost their cristae or these have shrunk to one pole. Fragments of mitochondrial membranes and some smaller particles can also be seen. Their density is similar to that found for liver mitochondria by Kuff \& Schneider (1954). By contrast, in fraction $B$ [Plate $4(2)$, rich in acetylcholine, mitochondria are almost completely absent, but there are large numbers of smaller particles, ranging in diameter from 0.3 down to about $0.02 \mu$. These on section appear as simple vesicles. There are also other structures which may be fragments of mitochondrial membranes and portions of the endoplasmic reticulum. A few of the larger particles resemble rat-liver lysosomes in appearance (Novikoff, 1957). It seems reasonable to assume that some at least of the particles seen in Plate 4 (2) are those containing acetylcholine. Electron micrographs of preparations of fraction $B$ in which the separation of SDH activity was less complete showed considerable numbers of the larger particles with the internal structure of mitochondria.

Counts of particle size were made of several micrographs each containing several hundred particles. The logarithms of particle diameters were found to be normally distributed (Fig. 4), the median diameter of particles of fraction $B$ being $0.065 \mu, \lambda 0.24$, and that of particles of fraction $C$ being $0.26 \mu, \lambda 0.22$, where $\lambda$ is the standard deviation of the logarithm (to base 10) of the diameters. Over $60 \%$ of the particles in fraction $B$ fell into the size range $(0.02-0.08 \mu)$ reported for synaptic vesicles (Palay, 1956). The distribution of particle diameters in fraction $C$ was not quite lognormal, but could be made so if it were corrected on the assumption that fraction $C$ contained $10 \%$ of particles from fraction $B$.

The appearance of the particles in fraction $A$ as seen with phase contrast is shown in Plate $4(1)$. Their nature has not yet been elucidated. They contain little ribonucleic acid or deoxyribonucleic acid and do not react like nuclei to nuclear stains; they are therefore probably not of nuclear or microsomal origin. They may be small enucleated cells, possibly derived from glial tissue.

\section{Distribution of active substances other than acetylcholine in the density gradient}

In order to gain some idea of the degree of homogeneity of the acetylcholine-particle preparation, the distribution of some other active substances in the density gradient was compared with that of acetylcholine. Particular interest attached to 5hydroxytryptamine (5-HT). This has been postulated to have a transmitter action in the central nervous system and has been stated to be located in mitochondria (Walaszek \& Abood, 1957). Because the stability of the acetylcholine-containing particles bore some resemblance to that of lysosomes (de Duve, Pressman, Gianetto, Wattiaux \& Appelmans, 1955), the distribution of two lysosomal enzymes, acid phosphatase and $\beta$-glucuronidase, was studied. There is evidence that rat brain contains lysosome-like particles (Beaufay, Berleur \& Doyen, 1957), but information about their sedimentation and other properties is lacking.

Distribution of 5-hydroxytryptamine in fractions. The 5-HT content of sucrose homogenates of guinea-pig brain was found to be between 0.9 and $1.9 \mu \mathrm{m}$-moles/g., which is near the values given by Correale (1957) and Walaszek \& Abood (1957), if $\mu \mathrm{mg}$. is read for $\mu \mu \mathrm{g}$. in the latter paper. About $25-40 \%$ of the total 5-HT in the homogenate was

\section{EXPLANATION OF PLATE 4}

1. Phase-contrast micrograph of fraction $A$ of guineapig brain. Wet preparation stained with osmium tetroxide.

2. Electron micrograph of ultra-thin section of pellet (fixed and stained in osmium tetroxide) embedded in methyl methacrylate resin, from fraction $B$ of guinea-pig brain. Large numbers of small particles $(a), 0.02-0.3 \mu$ in diameter, can be seen. Some appear in section as simple vesicles $(v)$.

3. Electron micrograph prepared in the same way as (2) from fraction $C$. Many typical mitochondria $(m)$ with lengths up to $1 \mu$ can be seen. A few smaller bodies $(a)$ similar to the larger particles in (2) are also present.

Fractions were prepared from the $P_{2}$ fraction by using the Spinco no. 40 head as described in the Methods section. 

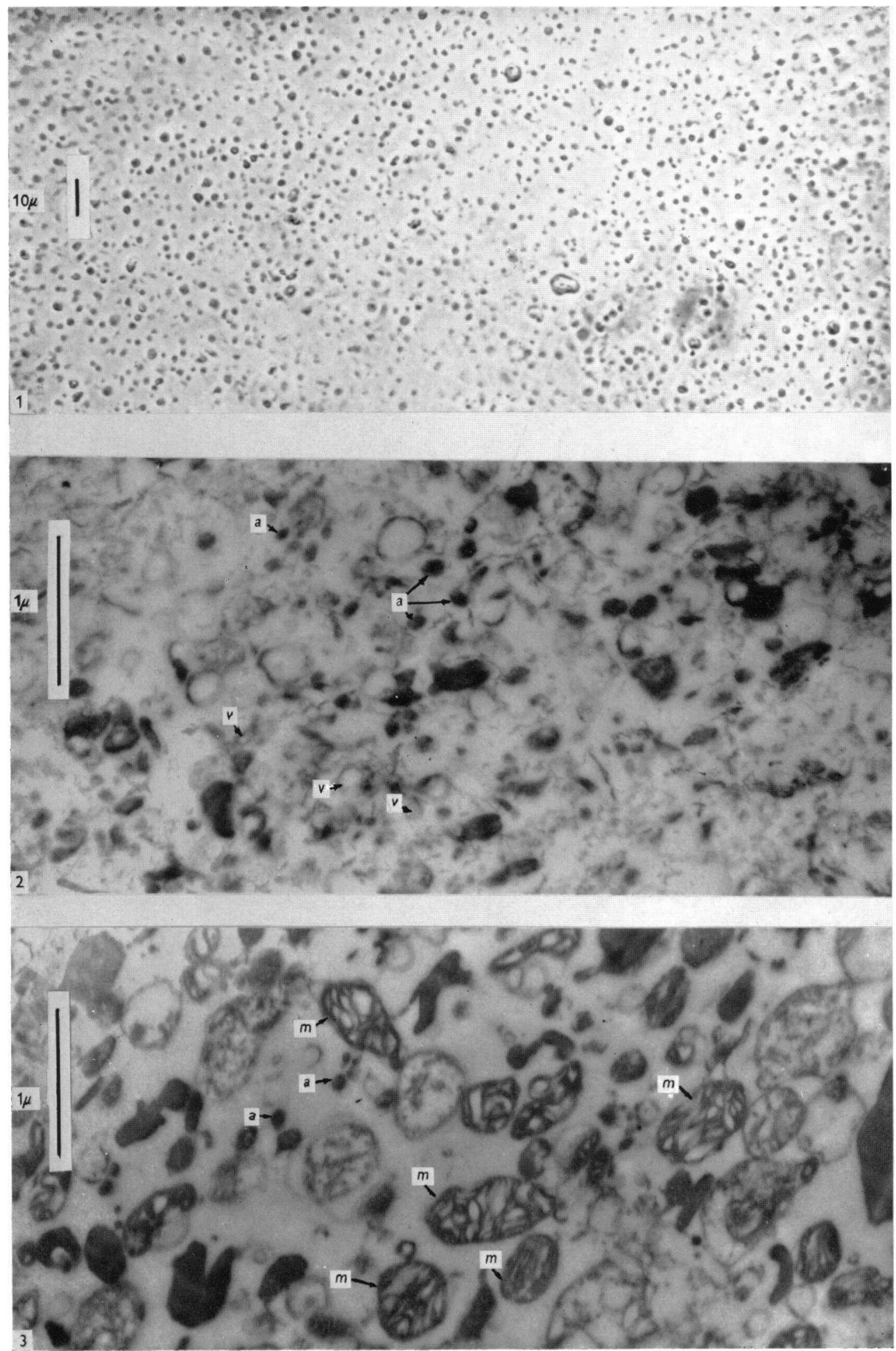

V. P. WHITTAKER-ThE ISOLATION AND CHARACTERIZATION OF ACETYLCHOLINE-CONTAINING PARTICLES FROM BRAIN 
found to be in the 'free' form; this was recovered in the supernatant fraction. The remainder was mainly in the $P_{2}$ fraction. On subfractionating the latter in a density gradient using the SW 39 head, most of the activity was found to be in the $B$ fraction, which also has a high acetylcholine content. The result of a typical experiment is given in Fig. 5. Particulate fractions, even after resuspension in fresh $0.32 \mathrm{M}$-sucrose, appeared to contain some free 5-HT. With $P_{2}$ this amounted to 7-35\% of the total 5-HT of the fraction. Since reasonably good recoveries of particulate 5-HT were attained on subfractionation, the particles could not have been losing 5-HT continuously during the preparation at $0^{\circ}$, and it was concluded that the free 5-HT in particulate fractions represented 5-HT liberated from the particles during the assay. In this respect 5-HT differs from acetylcholine, but the difference may be due to the higher temperature at which the 5-HT assays are carried out $\left(37^{\circ}\right.$ for the rat fundus compared with $20-22^{\circ}$ for the frog rectus).

Distribution of lysosome enzymes in fractions. Table 2 shows the distribution of acid phosphatase and $\beta$-glucuronidase in the various fractions and subfractions of a guinea-pig-brain homogenate. SDH and acetylcholine assays were carried out on the same fractions and are included for comparison. It will be seen that the two enzymes have different distributions in the density gradient, the distribution of acid phosphatase paralleling that of acetylcholine, while that of $\beta$-glucuronidase more closely resembles that of $\mathrm{SDH}$.

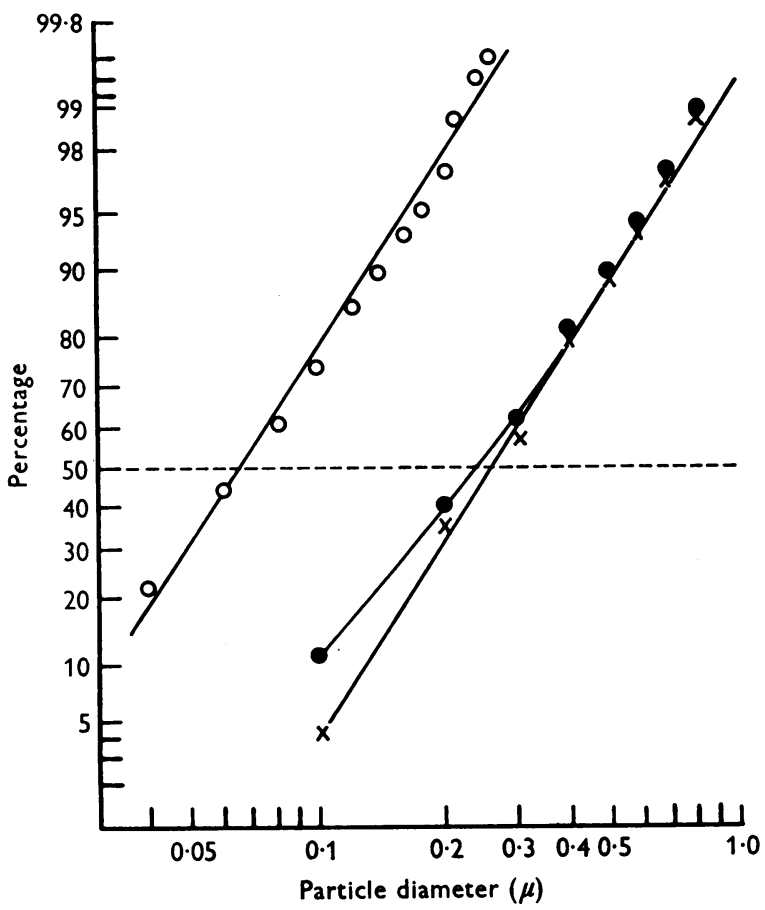

Fig. 4

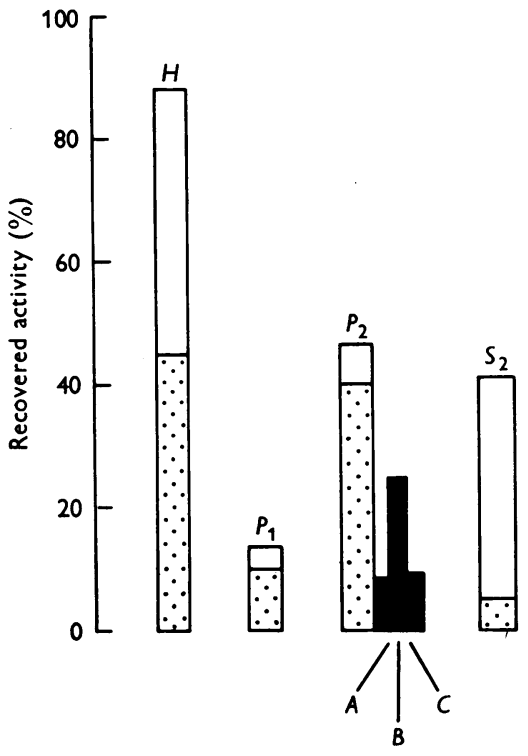

Fig. 5

Fig. 4. Lognormal distribution of particle size in subfractions $B$ and $C$ [Plate 4 (2 and 3)]. Total number of particles counted: $B, 1126 ; C, 289$. Ordinates, percentage of total population having indicated diameter and below, plotted on linear scale of probits; abscissae, particle diameters, plotted on logarithmic scale. O, Subfraction $B$; , subfraction $C$; $\times$, subfraction $C$ corrected for $10 \%$ contamination by subfraction $B$. It will be seen that the distribution of $B$ and the corrected distribution of $C$ lie close to the lognormal distributions indicated by the straight lines.

Fig. 5. Bound (dotted blocks) and free (white blocks) 5-hydroxytryptamine (5-HT) in a sucrose homogenate of guineapig brain $(H)$ and in the $P_{1}, P_{2}$ and $S_{2}$ fractions derived from it, expressed as a percentage of the total recovered activity. The black blocks show the distribution of activity in the three subfractions $(A, B$ and $C)$ of $P_{2}$, prepared in the SW 39 head. Total 5-HT content of H, $0.9 \mu \mathrm{m}$-mole/g. Recovery of free activity of $H$ in $S_{2}, 92 \% ;$ recovery of bound activity of $H$ in $P_{1}, P_{2}$ and $S_{2}, 125 \%$. 
Table 2. Distribution of acetylcholine, succinic dehydrogenase and lysosome enzymes in subcellular fractions of guinea-pig brain

The figures are the activity expressed as a percentage of total recovered activity. $A, B$ and $C$ were obtained from $P_{2}$ by using the Spinco SW 39 head. The eserine-free sucrose homogenate of guinea-pig brain from which all the fractions were prepared had the following activities: acetylcholine, 12.8 $\mu \mathrm{m}$-moles/g., SDH, $13200 \mathrm{u} . / \mathrm{g}$., acid phosphatase (substrate, disodium phenylphosphate) 3.0 mg. of $\mathrm{P} / \mathrm{hr}$./g., $\beta$-glucuronidase, 285 G.U./g.

$\begin{array}{lcrcc}\text { Fraction } & \text { Acetylcholine } & \text { SDH } & \text { Acid phosphatase } & \beta \text {-Glucuronidase } \\ P_{1} & 12 & 23 & 24 & 30 \\ P_{2} & 70 & 77 & 42 & 51 \\ S_{2} & 18 & 0 & 34 & 19 \\ \text { Recovery } & 100 & 74 & 113 & 80 \\ A & 19 & 0 & 26 & 14 \\ B & 62 & 26 & 59 & 30 \\ C & 19 & 74 & 15 & 56 \\ \text { Recovery } & 93 & 59 & 136 & 93\end{array}$

Factors influencing the release of particulate acetylcholine and 5-hydroxytryptamine: further evidence for 'labile' and 'stable' forms of bound acetylcholine and for an ionic component in the latter

Previous work (Brodkin \& Elliott, 1953; Hebb \& Whittaker, 1958) has indicated that about $50 \%$ of the particle-bound acetylcholine is in a labile form which is readily released by relatively mild treatments such as osmotic dilution, freezing and thawing, or dialysis. The rest is in a more stable form which requires treatment with hydrochloric acid, trichloroacetic acid or ether for release. The stability of this second fraction is attested to by numerous earlier observations (for references see Feldberg, 1945), which have shown that it is not released by repeated washing or grinding of particulate material and is resistant to cholinesterases.

Further investigation of the conditions under which acetylcholine is released was undertaken in an attempt to clarify the nature of the binding forces and the mechanism of acetylcholine release in vivo. Conditions which released the labile form only-ageing at $0^{\circ}$, osmotic dilution, freezing and thawing, shaking with glass Ballotini beads, treatment with cobra venom-are all those which might be expected to increase the permeability of subcellular particles without disrupting them completely, thus confirming earlier suggestions that the labile fraction represents free acetylcholine sequestered within an easily damaged membrane. Conditions which released both forms included incubation for $1 \mathrm{hr}$. at $37^{\circ}$, treatment with organic solvents and exposure to $\mathrm{pH}$ values of 4 or less; the first two and perhaps the last would be expected to cause extensive demage to subcellular structures, possibly by processes of autolysis or denaturation; in addition, the displacement of the stable form by $\mathrm{H}^{+}$ions might point to the presence of an ionic component in the binding.

Provided that the particles were not subjected to even mildly disruptive procedures they could be centrifuged and washed repeatedly or exposed to cholinesterases, certain drugs and inorganic ions with little or no loss of either fraction. Since released acetylcholine (or added free acetylcholine) was, by contrast, rapidly destroyed by the cholinesterase invariably present in the preparations, eserine $(50 \mu \mathrm{M})$ was always added, either to the fraction being studied or to the original homogenate from which it was prepared, when the release of acetylcholine was to be followed directly by assay of the liberated ester. Some of the substances tested (e.g. inorganic ions) interfered with the assay; release was then measured by comparing the acetylcholine content of treated particles with that of a control sample after collecting them by centrifuging. Experiments were usually carried out on the $P_{2}$ fraction; the $B$ fraction behaved similarly, except that the proportion of labile particulate acetylcholine was slightly smaller.

Freezing and thawing. Samples of $P_{\mathbf{2}}$ were withdrawn after freezing and thawing varying numbers of times and centrifuged, and free and bound acetylcholine determined on precipitate and supernatant. All the particulate acetylcholine was found to be in the bound form, and all the supernatant in the free form. Recoveries of total acetylcholine from precipitate and supernatant were close to $100 \%$. The freezing and thawing caused a progressive release of acetylcholine into the supernatant (Fig. 6a), but this was only about $50 \%$ complete after 20 freezings and thawings and was not thereafter much increased. After 30 freezings and thawings, the total acetylcholine of the preparation began to decline.

Osmotic pressure. Fig. $6 b$ shows the release at $0^{\circ}$ of acetylcholine from particles from $P_{2}$ suspended in sucrose solutions having approximately half, onefifth and one-tenth the osmotic pressure of the cell sap. Acetylcholine is released relatively slowly in $0.16 \mathrm{M}-$, more rapidly in $0.08 \mathrm{M}$ - and very rapidly in $0.032 \mathrm{M}$-sucrose, but the process again had an end point at about $50 \%$ of the total acetylcholine. 
Moderately hyperosmotic conditions (2-3 times iso-osmotic), whether brought about by the addition of sucrose or sodium chloride to the suspension in $0.32 \mathrm{M}$-sucrose, had little or no effect on the particulate acetylcholine.

Shaking. Mechanical disintegration by shaking in the Mickle shaker at $50 \mathrm{c}$./sec. in the presence of glass Ballotini beads also released about $50 \%$ of the particulate acetylcholine.

Hydrogen-ion concentration. The effect of $\mathrm{H}^{+}$ion concentration on the release of acetylcholine at $0^{\circ}$ is shown in Fig. 6c. At pH 4 most of the acetylcholine is released in $20 \mathrm{~min}$. even at $0^{\circ}$; above pH 4.5 the release is very much slower.

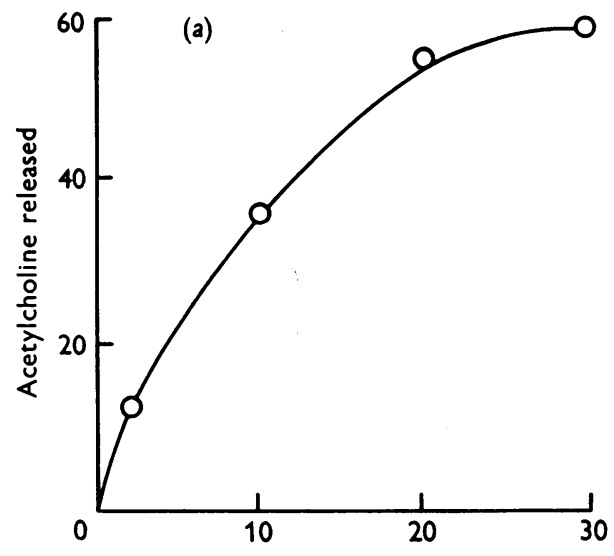

Number of times frozen and thawed

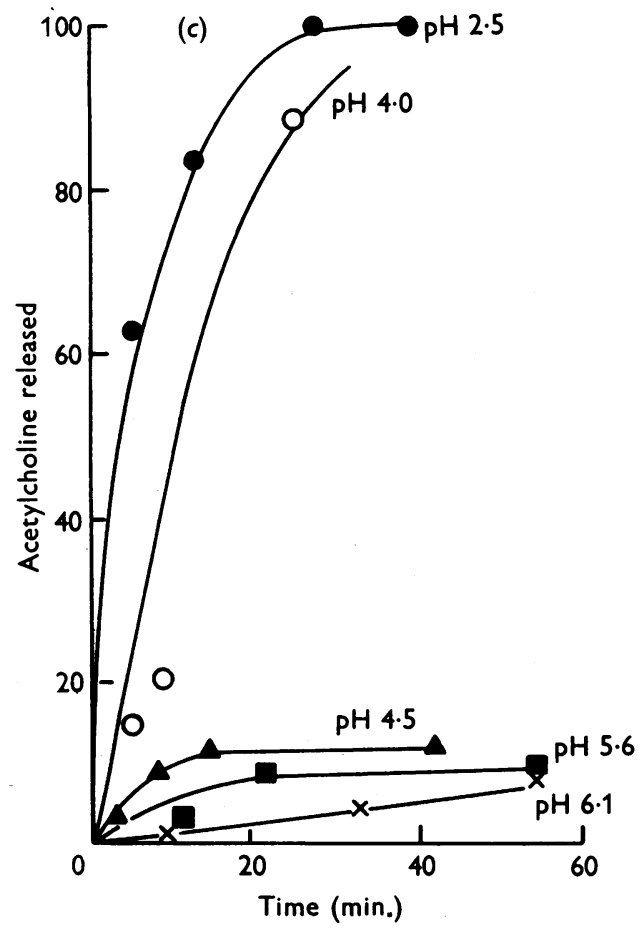

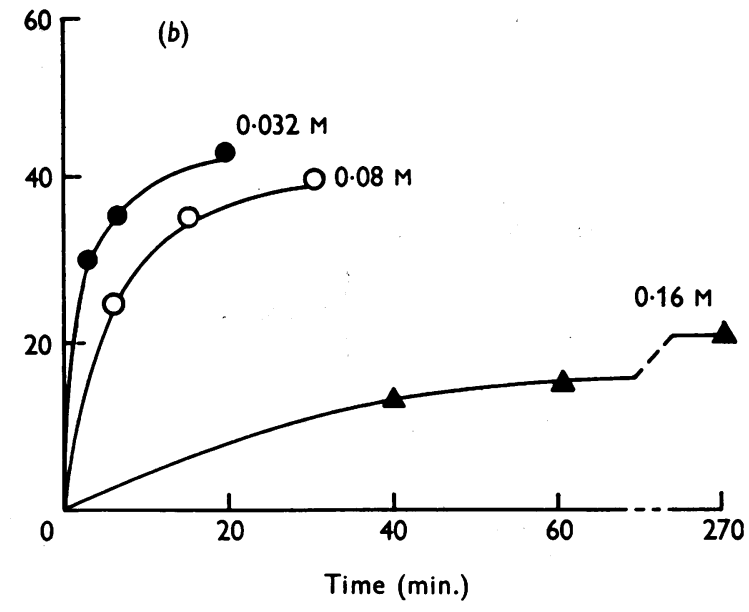

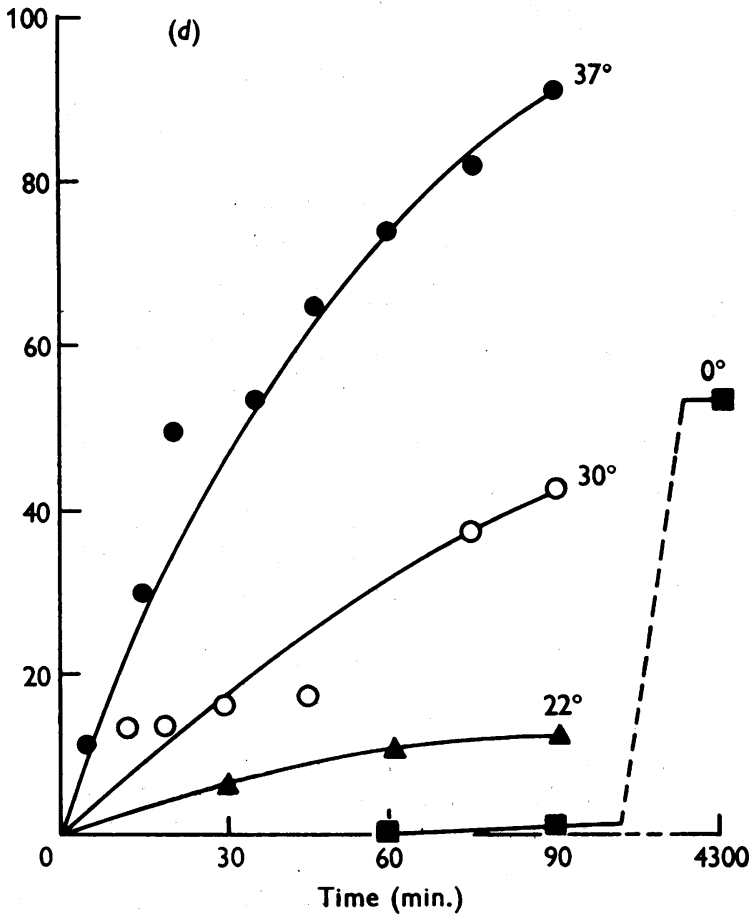

Fig. 6. Release of acetylcholine from $P_{8}$ fraction $(a)$ by repeated freezing and thawing, $(b)$ in hypo-osmotic sucrose at $0^{\circ}$, (c) at different $\mathrm{pH}$ values at $0^{\circ},(d)$ at different temperatures. The acetylcholine released is expressed as a percentage of the sum of released and bound acetylcholine remaining at the end of the experiment. (a), Rabbit; (b-d), guinea pig. Total aeetylcholine of fractions (a) $2 \cdot 8,(b) 3 \cdot 0,(c) 3 \cdot 6,(d) 2 \cdot 8 \mu \mathrm{m}-\mathrm{moles} / \mathrm{ml}$. 
Table 3. Effect of various substances on release of acetylcholine from $P_{2}$ fraction of guinea-pig brain in sucrose containing eserine

All experiments were carried out at $0^{\circ}$ unless otherwise stated. Total acetylcholine of fractions $(\mu \mathrm{m}-\mathrm{moles} / \mathrm{ml}):.(a) 4 \cdot 8$, (b) 4.4, (c) 1.6, (d) 5.6, (e) 4.0, (f) 3.2; (a) eserine-free $P_{\mathbf{2}}$, (c) eserine-free homogenate.

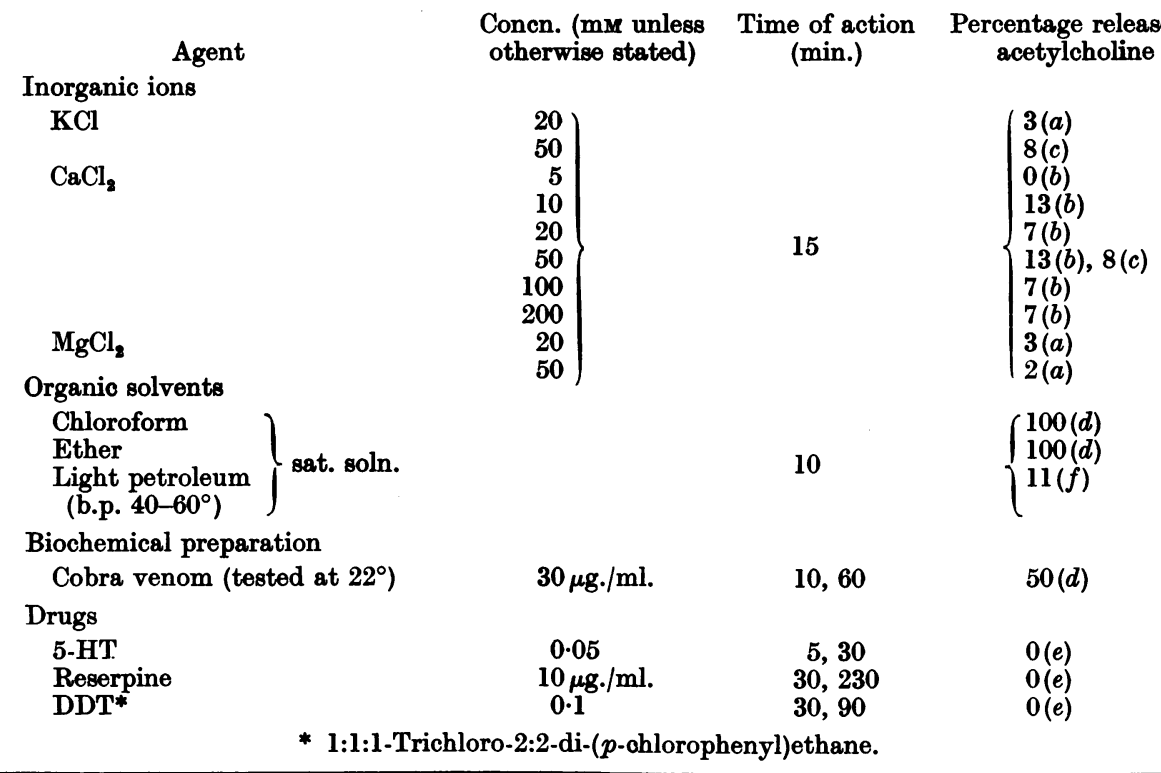

Temperature. The effect of temperature on the release of acetylcholine is shown in Fig. $6 d$. It will be seen that acetylcholine is almost completely released by incubating the particles at $37^{\circ}$ for $1 \mathrm{hr}$. At $22^{\circ}$, only about $10 \%$ of the acetylcholine was released in this time. At $0^{\circ}$ release is extremely slow, having reached only $54 \%$ in 3 days. The bound particulate acetylcholine still present at this time was all in the 'stable' form, as was shown by its release by ether or acid treatment but not by exposure to 0.032 M-sucrose. Thus 'labile' acetylcholine seems to be lost preferentially.

Inorganic ions, organic substances and enzymes. The result of these experiments are summarized in Table 3. $\mathbf{K}^{+}, \mathbf{M g}^{2+}$ and $\mathrm{Ca}^{2+}$ ions had little effect, though their presence caused the particles to clump and sediment more readily on centrifuging than did the control samples. Organic solvents (chloroform, ether) liberated bound acetylcholine completely. Cobra venom, in the highest concentration tested, liberated only about $50 \%$ of the particulate acetylcholine. Presumably the lecithinase in the venom damages the particles sufficiently to allow the labile fraction of particulate acetylcholine to diffuse out, but does not affect the stable fraction. The stable fraction could be released by treating the cobra-venom-treated particles with ether.

Effect of cholinesterase. As already mentioned, brain cholinesterase does not destroy particulate acetylcholine (as shown by the survival of this in preparations made in eserine-free sucrose) although
Table 4. Action of cholinesterase on particulate acetylcholine

The $P_{2}$ fraction was prepared from an eserine-free sucrose homogenate of guinea-pig brain. Water-treated particles were obtained by centrifuging a sample of $\boldsymbol{P}_{2}$ and resuspending the precipitate in an equal volume of water. Acetylcholine and enzyme (purified bovine-red-cell cholinesterase, Stearns Winthrop Inc.; activity $30 \mathrm{u} . / \mathrm{mg}$.) were added in $0.32 \mathrm{M}$-sucrose, with extra $0.32 \mathrm{M}$-sucrose where necessary to give a total volume of $1.2 \mathrm{ml}$. in each tube. The tubes were kept for $10 \mathrm{~min}$. at room temperature and the reaction was stopped by the addition of eserine $(5 \mu \mathrm{g}$. in $0.05 \mathrm{ml}$.). The tubes were brought to $\mathrm{pH} 4$ and heated for $10 \mathrm{~min}$. at $100^{\circ}$ to release bound acetylcholine before assay.

Total acetylcholine

\begin{tabular}{clc} 
Tube & \multicolumn{1}{c}{ Additions } & $\begin{array}{c}\text { remaining } \\
(\mu \mathrm{m}-\mathrm{moles})\end{array}$ \\
1 & Acetylcholine $(10 \mu \mathrm{m}-\mathrm{moles})$ & 10 \\
2 & Acetylcholine + enzyme $(0 \cdot 5 \mathrm{mg})$. & 0 \\
3 & Particles (1 ml. of $\left.P_{2}\right)$ & $3 \cdot 1$ \\
4 & Particles +enzyme & $\mathbf{3 \cdot 2}$ \\
5 & Particles + acetylcholine + enzyme & $\mathbf{4} \cdot 0$ \\
6 & Water-treated particles (1 ml. $)+$ & $1 \cdot 2$ \\
& enzyme & $1 \cdot 2$ \\
7 & Water-treated particles + acetyl- & \\
& choline +enzyme
\end{tabular}

it does destroy free acetylcholine. The effect of cholinesterase on particulate acetylcholine was, therefore, studied further with a highly purified preparation of bovine-red-cell cholinesterase. The results obtained are illustrated in Table 4. It will 
be seen that added enzyme was unable to destroy particulate acetylcholine (compare tubes 3 and 4), although the enzyme destroyed three times as much free acetylcholine (compare tubes 1 and 2 ) in the same time. That this failure was not due to destruction or inhibition of the enzyme by the particles is shown in tube 5, in which the enzyme, acting on a mixture of the particles and added acetylcholine, destroyed an amount almost equal to that of free acetylcholine added. When particulate acetylcholine was partially released by treating the particles with water, the released acetylcholine was destroyed (tube 6), the amount of acetylcholine remaining corresponding to the stable fraction observed in experiments of the type illustrated by Fig. $6 b$. The survival of this fraction of acetylcholine was not due to inhibition of the added cholinesterase, since added acetylcholine was completely destroyed in the presence of the watertreated particles (tube 7). The change in the particles induced by water treatment is thus evidently not sufficiently drastic to permit access of cholinesterase to the stable fraction.

The amount of acetylcholine remaining in tube 5 was greater than in the corresponding control tube (4), although the concentration of enzyme should have been sufficient to destroy all the added acetylcholine. The particles appeared to have 'protected' about $8 \%$ of the added acetylcholine from the cholinesterase. Further investigation showed that this was due to an uptake of acetylcholine from the medium by the particles. It was not due to synthesis of acetylcholine by the particles from the products of the enzymic hydrolysis, since particles were unable to increase their acetylcholine content at the expense of an equivalent amount of choline and acetic acid added to the medium. Aged or water-treated particles or particles, acidified to $\mathrm{pH} 4 \cdot 0$ and then neutralized, were unable to take up acetylcholine from the medium. This suggests that the process is an active one and dependent on an intact membrane.

Inability of subcellular particles from liver to bind acetylcholine. The possibility was considered that the binding of acetylcholine by brain particles was an artifact. Accordingly rat liver, a tissue with a negligible acetylcholine content, was homogenized in $0.32 \mathrm{M}$-sucrose in the presence and absence of $50 \mu \mathrm{M}$-eserine and acetylcholine (10 $\mu \mathrm{m}$-moles $/ \mathrm{ml}$.), and then separated into the various subcellular fractions as for brain. If eserine was present, all the acetylcholine was recovered in the supernatant fraction; if eserine was absent, all the acetylcholine was destroyed, presumably by the liver cholinesterase. When acetylcholine $(10 \mu \mathrm{m}-\mathrm{moles} / \mathrm{ml}$. $)$ was added to an eserine-free $P_{2}$ fraction from rat liver, there was a steady fall in free acetylcholine, unaccompanied by any uptake of acetylcholine by the particles. While it is obviously impossible to reproduce the conditions prevailing in brain with another tissue, these experiments certainly do not support the idea that the binding of acetylcholine by brain particles is an artifact.

Model experiments with an ion-exchange resin. Since the critical range of $\mathrm{pH}$ in which the stable fraction of bound acetylcholine begins to be displaced from the particles is between 4.0 and 4.5 (Fig. 5c), it was considered that the main bond between stably bound acetylcholine and the particle matrix might be an ionic one between the quaternary nitrogen of acetylcholine and a carboxylic acid group. Choline esters are known to be adsorbed by carboxylic acid ion-exchange resins (Gardiner \& Whittaker, 1954; Keyl, Michaelson \& Whittaker, 1957), so it was decided to compare the properties of bound acetylcholine with those of suspensions of resin containing adsorbed choline esters of varying affinity. Three pharmacologically active esters, acetyl-, isovaleryl- and urocanylcholine, of increasing affinity, were adsorbed on samples of the carboxylic acid resin XE-97 (Rohm \& Haas Co., Philadelphia, Pa., U.S.A.) in column form. The resin was well washed and suspended in water. The supernatants from these suspensions were tested on the frog rectus and remained free of ester. When the suspensions themselves were tested, those containing acetylcholine were as active as would have been expected if all the acetylcholine had been displaced from the resin by the cations of the frog Ringer solution, and the ability of frog Ringer solution to displace the ester was confirmed. By contrast, resin suspensions containing the more strongly adsorbed isovaleryland urocanyl-choline were inactive. However, heating these suspensions at $100^{\circ}$ for $10 \mathrm{~min}$. at pH 4.0 displaced the esters and the supernatants from resins so treated were fully active. It thus seems likely that ionic forces alone would be unable to account for the stability of stable bound acetylcholine, but they might nevertheless provide the main component of the binding forces. The further study of these binding forces has been handicapped by the failure so far to discover ways of reversibly depleting the particles of acetylcholine.

Release of 5-hydroxytryptamine. Investigation of the release of 5-HT from particulate fractions was complicated by $(a)$ the spontaneous release during assay, referred to in a previous section, $(b)$ destruction of released 5-HT. Provided that the monoamine oxidase inhibitor 1-isonicotinoyl-2-isopropylhydrazine phosphate (iproniazid) was added beforehand in a final concentration of $\mathrm{mM}$, the pattern of release of 5-HT resembled in general that of acetylcholine in the presence of eserine, although iproniazid was not as effective as a stabilizing agent for 5-HT as eserine was for 
acetylcholine. Thus ether treatment resulted in total release of particle-bound 5-HT, while hypoosmotic dilution (resuspension of particles from the $P_{2}$ fraction in 0.032 M-sucrose) gave evidence of a labile fraction of bound 5-HT, a maximum of $40-50 \%$ of the total 5-HT being liberated under these conditions after $45 \mathrm{~min}$. In the absence of iproniazid, liberated 5-HT was rapidly destroyed, as was acetylcholine in the absence of eserine.

The behaviour of 5-HT, however, did not exactly parallel that of acetylcholine. Even in the absence of iproniazid, there was free 5-HT present in the supernatant fraction of sucrose homogenates and added 5-HT was stable in contact with untreated particles. Nevertheless, disruptive treatment led to destruction of added 5-HT as well as of released endogenous 5-HT unless iproniazid were added beforehand. It was therefore concluded that, unlike cholinesterase, the iproniazid-sensitive factor (presumably monoamine oxidase) responsible for the destruction of 5-HT is present in an inactive form in untreated particles and is released under the same conditions as is 5-HT. Evidence that monoamine oxidase is not freely accessible in vivo has been presented by Udenfriend, Weissbach \& Bogdanski (1957). Normal methods of determining monoamine oxidase activity in vitro would be expected to be highly disruptive to intracellular particles and would fail to reveal the existence of an intracellular permeability barrier to substrates and inhibitors.

\section{DISCUSSION}

The resolution of homogenates into morphologically identifiable constituents is much more difficult with brain than with liver, the tissue most investigated from this point of view. The so-called mitochondrial fraction is much more complex; nevertheless, it has been successfully separated into three well-defined subfractions on the basis of density differences. The densest of these has been shown to consist mainly of mitochondria and might be a convenient starting point for a pure preparation of these organelles for metabolic studies. The lightest consists of relatively large, structureless particles which have not so far been identified. The particles of intermediate density have been distinguished from mitochondria on both morphological and biochemical evidence and contain a significant proportion of the bound acetylcholine and 5-HT of the brain as well as much of the acid phosphatase. The only well-defined structures known to be present in the central nervous system with a comparable size range are the synaptic vesicles. Even if these are in reality tubules rather than vesicles, as suggested by some investigators (Gray, 1959), it is conceivable that they might break up on homogenization to give particles of the size range observed, just as the smaller endoplasmic reticulum is believed to give rise to microsomes.

The presence in this subfraction of two pharmacologically active components with different distributions in whole brain suggest that it consists of particles of more than one type; however, the conditions under which acetylcholine and 5-HT are released are sufficiently similar to suggest that the particles containing these two substances are closely related. Since material denser than $1 \cdot 2 \mathrm{M}$ sucrose was not present in this preparation, the 5-HT particles in brain must differ from those isolated from intestinal mucosa by Baker (1958). Previous evidence on the localization of bound 5-HT in brain has been conflicting (Walaszek \& Abood, 1957; Bogdanski, Weissbach \& Udenfriend, 1956).

A study of the factors influencing the release of acetylcholine from the particles has not enabled the mechanism of acetylcholine release in vivo to be identified as yet. The particles appear to be stable at $0^{\circ}$ to ions such as $\mathrm{Ca}^{2+}, \mathrm{Mg}^{2+}$ and $\mathrm{K}^{+}$, though the presence of these ions caused them to coacervate, so that it is unlikely that ionic shifts themselves are the determining factor. However, this study has confirmed earlier suggestions that about half of the bound acetylcholine is present in a highly labile form and behaves as though it were imprisoned in the free state inside a membrane which is readily damaged by osmotic dilution, freezing and thawing and other mildly disruptive procedures. The remaining portion of the particlebound acetylcholine is more firmly attached and requires more drastic conditions for release-incubation at $37^{\circ}$, exposure to $\mathrm{pH}$ values of 4.0 or less or treatment with organic solvents. This implies a fairly strong chemical bond between acetylcholine and the particle matrix. The most obvious one would be an ionic bond between the quaternary nitrogen of acetylcholine and an acidic group, reinforced perhaps by other short-range intermolecular forces of the type that have been discussed in connexion with the binding of esters by cholinesterase (Adams \& Whittaker, 1950) and other specific biological interactions. The model experiments with a carboxylic acid ion-exchange resin containing adsorbed choline esters gave limited support to this idea.

The concept of the acetylcholine-containing particle which emerges from this work is summarized in Fig. 7. The particle is envisaged as a simple vesicle, about $0.05 \mu$ in diameter, containing some acetylcholine in solution and some bound ionically to carboxylic acid groups in the particle wall. This fraction of acetylcholine is shown within the particle, because it remains inaccessible to cholinesterase even when the permeability of the particle is increased by mild disruptive techniques. 
The particle is also shown to contain choline acetylase (Hebb \& Whittaker, 1958) but not acetocholinesterase, because recent work by Toschi (1959) and Aldridge \& Johnson (1959) has shown that this component of the acetylcholine system is localized primarily in the microsomal fraction and that its presence in other fractions is due to microsomal contamination. Toschi has also found that, when the microsomal fraction is dissociated into an RNA-rich portion (consisting mainly of Palade granules) and an RNA-poor fraction (consisting mainly of structureless vesicles derived from the membranous component of the endoplasmic reticulum), the acetocholinesterase is concentrated in the latter portion. The dissociation between RNA and acetocholinesterase is also shown by the more diffuse distribution of the latter among the primary fractions of the sucrose homogenate (Aldridge \& Johnson, 1959; V. P. Whittaker, un. published observations), suggesting that the acetocholinesterase may be bound to RNA-poor portions of the endoplasmic reticulum. Since in current cytochemical thinking no clear distinction is made between the limiting membrane of the cell and the endoplasmic reticulum, these RNA-poor portions of the latter might correspond to regions of the postsynaptic neurone nearest to the presynaptic nerve terminals. The suggested relationship of the

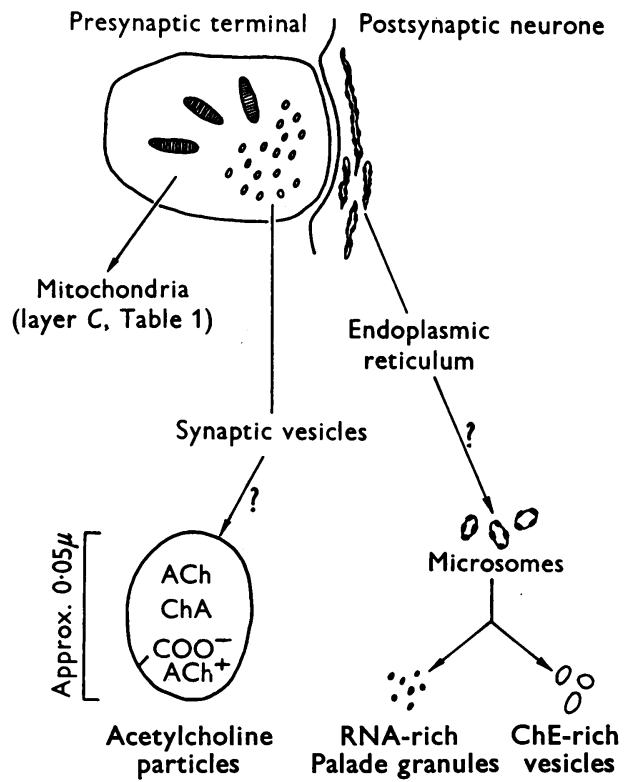

Fig. 7. Schematic representation of a synapse (based on electron micrographs of Palay, 1956) showing hypothetical relationship of subcellular structures to cholinesterase-rich vesicles (Toschi, 1959) and acetylcholine particles (this paper). Abbreviations: ChE, acetocholinesterase; $\mathrm{ACh}$, acetylcholine; ChA, choline acetylase. two types of particles to each other and to the morphology of the synapse is indicated in Fig. 7.

The behaviour of bound acetylcholine as revealed by the experiments carried out on the $P_{2}$ fraction and the acetylcholine-rich fraction derived from it is in general consistent with most previous work on the subject, though much of this was done with homogenates in water or sodium chloride solution which must have contained acetylcholine particles in a more or less damaged state. Thus Cavanaugh \& Tobias (1949) showed that bound acetylcholine was liberated from water homogenates of brain on incubation, and Brodkin \& Elliott (1953) distinguished between two forms of bound acetylcholine in saline homogenates. The release of bound acetylcholine by ether parallels the activation of particulate choline acetylase by ether (Hebb \& Smallman, 1956). The increased synthesis of acetylcholine observed in chloroform, or ether-treated brain minces (Stedman \& Stedman, 1937,1939 ) or venom-treated brain slices (Braganca \& Quastel, 1952) is consistent with the release of acetylcholine from chloroform-, ether- or venomtreated particles (Table 3), and suggests that the rate-limiting factor in acetylcholine synthesis in inactive neurones may be the accumulation of intraparticulate acetylcholine.

So far as they show that procedures which drastically affect the integrity of the particles release all the bound acetylcholine, the present findings are not consistent with reports of an ethanol-soluble form of bound acetylcholine in brain (Abdon \& Hammarskjöld, 1944; Loewi \& Hellauer, 1938). An attempt to repeat these findings was unsuccessful; the acetylcholine extracted by ethanol from brain under conditions approximating to those described by Abdon \& Hammarskjöld was all in the free form.

Although the two forms of particle-bound acetylcholine have been represented in Fig. 7 as occurring in the same particle, there is at present no conclusive evidence that this is so. There may be two kinds of particle or a spectrum of particles. However, the release of approximately $50 \%$ of the bound acetylcholine by such diverse procedures as treatment with cobra venom, freezing and thawing, shaking with Ballotini beads and hypotonic dilution is difficult to reconcile with the second of these alternatives.

\section{SUMMARY}

1. The crude mitochondrial fraction of sucrose homogenates of rabbit and guinea-pig brain was resolved into three main fractions by equilibrium centrifuging in a density gradient. These were: $A$, particles less dense than $0.8 \mathrm{M}$-sucrose, diameter 2-5 $\mu$; $B$, particles denser than $0.8 \mathrm{M}$-sucrose and lighter than $1 \cdot 2 \mathrm{M}$-sucrose, diameter $0.02-0.3 \mu$ 
(medien, $0.065 \mu$ ); $C$, particles denser than 1.2 Msucrose, diameter 0.02-1.0 $\mu$ (median 0.25 $\mu$ ).

2. The particles of fraction $C$ were identified on morphological and biochemical evidence as mitochondria.

3. Most of the particle-bound acetylcholine and 5 -hydroxytryptamine was localized in the $B$ layer. Over $60 \%$ of the particles of this fraction had the size range $(0.02-0.08 \mu)$ reported for synaptic vesicles, and appeared as simple vesicles in electron micrographs.

4. The distribution of two lysosome enzymes was also studied. One of these, acid phosphatase, was mainly in the $B$ layer, the other, $\beta$-glucuronidase, mainly in the $C$ layer. It would seem that the lysosome hypothesis requires modification when applied to brain.

5. A study was made of the factors determining the release of acetylcholine and 5-hydroxytryptamine. Further evidence was obtained for two forms of bound acetylcholine-a labile fraction released by mildly disruptive techniques which probably alter the permeability of the particles and permit the outward diffusion of free acetylcholine contained within them, and a more stable fraction which is held by chemical forces, including ionic links, to the particle matrix.

I am most grateful to Dr K. M. Smith and Mr G. J. Hills for the electron micrographs, to $\mathrm{Dr}$ W. N. Aldridge for access to unpublished work, and to Dr J. H. Gaddum for demonstrating to me the applicability of the lognormal distribution to the study of particle sizes and for the calculations embodied in Fig. 4. I am also greatly indebted to Miss J. M. Gilson and Mr G. Dowe for their skilful assistance.

\section{REFERENCES}

Abdon, N.-O. \& Hammarskjöld, S. O. (1944). Acta physiol. scand. 8, 75.

Adams, D. H. \& Whittaker, V. P. (1950). Biochim. biophys. Acta, 4, 543.

Aldridge, W. N. \& Johnson, A. (1959). Biochem. J. (in the Press).

Baker, R. V. (1958). J. Physiol. 143, 80 P.

Beaufay, H., Berleur, A. M. \& Doyen, A. (1957). Biochem.J. 66, 32P.

Berthet, J. \& de Duve, C. (1951). Biochem. J. 50, 174.

Bodian, D. (1942). Physiol. Rev. 22, 140.

Bogdanski, D. F., Weissbach, H. \& Udenfriend, S. (1956). J. Neurochem. 1, 272.
Braganca, B. M. \& Quastel, J. H. (1952). Nature, Lond., $169,695$.

Brodkin, E. \& Elliott, K. A. C. (1953). Amer. J. Physiol. 173, 437.

Cavanaugh, D. J. \& Tobias, J. M. (1949). Fed. Proc. 8, 22.

Chang, C. H. \& Gaddum, J. H. (1933). J. Physiol. 76, 255.

Cohn, P. \& Richter, D. (1956). J. Neurochem. 1, 166.

Correale, P. (1957). J. Neurochem. 1, 22.

de Duve, C., Pressman, B. C., Gianetto, R., Wattiaux, R. \& Appelmans, F. (1955). Biochem. J. 60, 604.

de Robertis, E. D. P. \& Bennett, H. S. (1955). J. biophys. biochem. Cytol. 1, 47.

de Robertis, E. \& Franchi, C. M. (1956). J. biophys. biochem. Cytol. 2, 307.

del Castillo, J. \& Katz, B. (1956). Progr. Biophys. 6, 121.

Eccles, J. C. (1957). The Physiology of Nerve Cells. Baltimore: The Johns Hopkins Press.

Feldberg, W. (1945). Physiol. Rev. 25, 596.

Gardiner, J. E. \& Whittaker, V. P. (1954). Biochem. J. 58, 24.

Gray, E. G. (1959). J. Physiol. 145, 25 P.

Hebb, C. O. (1957). Physiol. Rev. 37, 196.

Hebb, C. O. \& Smallman, B. N. (1956). J. Physiol. 134, 385.

Hebb, C. O. \& Whittaker, V. P. (1958). J. Physiol. 142, 187.

Hogeboom, G. H., Claude, A. \& Hotchkiss, R. D. (1946). J. biol. Chem. 165, 615.

Kerr, L. M. H. \& Levvy, G. A. (1951). Biochem. J. 48, 209.

Keyl, M. J., Michaelson, I. A. \& Whittaker, V. P. (1957). J. Physiol. 139, 434.

Kuff, E. L. \& Schneider, W. C. (1954). J. biol. Chem. 206, 677.

Loewi, O. \& Hellauer, H. (1938). Pfiüg. Arch. ges. Physiol. $240,449$.

Luft, J. H. (1956). J. biophys. biochem. Cytol. 2, Suppl. 229.

Novikoff, A. B. (1957). Symp. Soc. exp. Biol. 10, 92.

Palay, S. L. (1956). J. biophys. biochem. Cytol. 2, Suppl. 193.

Robertson, J. D. (1956). J. biophys. biochem. Cytol. 2, 381.

Stedman, E. \& Stedman, E. (1937). Biochem. J. 31, 817.

Stedman, E. \& Stedman, E. (1939). Biochem. J. 33, 811.

Stone, W. E. (1955). Arch. Biochem. Biophys. 59, 181.

Toschi, G. (1959). Exp. Cell. Res. 16, 232.

Udenfriend, S., Weissbach, H. \& Bogdanski, D. F. (1957). J. Pharmacol. 120, 255.

Vane, J. R. (1957). Brit. J. Pharmacol. $12,344$.

Walaszek, E. J. \& Abood, L. G. (1957). Fed. Proc. 16, 133.

Whittaker, V. P. (1958a). Biochem. J. 68, 21 P.

Whittaker, V. P. (1958b). Abstr. 4th Int. Congr. Biochem., Vienna, p. 74.

Whittaker, V. P. (1959). Biochem. Pharmacol. 1, 351. 